\title{
eBUX of OERs for PTC
}

\author{
Student and Faculty eBook User Experiences (eBUX) of Open Educational Resources (OERs) for \\ Professional and Technical Communication (PTC) \\ Henry A. Covey \\ Professional \& Technical Communication, Portland State University, USA
}

covey@pdx.edu

\begin{abstract}
This report analyzes the digital/electronic textbook user experience (eBUX) of web-based open educational resources (OERs) for professional and technical communication (PTC). Data and information were gathered from students enrolled in introductory PTC courses (with IRB oversight and input from faculty and writing program directors) via online surveys (Google Forms), collaborative documents (Google Docs), remote interviews (Zoom), learning management system analytics (Desire2Learn), workshop documentation (pre-pandemic), and email correspondence. User research revealed issues of use and usability with web-based open-access PTC textbooks related to functional specifications, content requirements, interface and interaction design, information architecture, navigation, and aesthetics. The conclusion discusses the evolution of digital OERs for PTC over the past quarter century and reflects on their future.
\end{abstract}

\section{CCS CONCEPTS}

- Human-centered computing $\rightarrow$ Interaction design; Interaction design theory, concepts and paradigms; • Social and professional topics $\rightarrow$ Professional topics; Computing education; Adult education; $\bullet$ Applied computing $\rightarrow$ Education; E-learning.

\section{KEYWORDS}

User experience, UX, open educational resource, OER, online textbook, software design methods \& principles, digital humanities \& design, technical communication, ebooks, Pressbooks, WordPress, Manifold

\section{ACM Reference Format:}

Henry A. Covey. 2021. eBUX of OERs for PTC: Student and Faculty eBook User Experiences (eBUX) of Open Educational Resources (OERs) for Professional and Technical Communication (PTC). In The 39th ACM International Conference on Design of Communication (SIGDOC '21), October 12-14, 2021, Virtual Event, USA. ACM, New York, NY, USA, 16 pages. https://doi.org/10.1145/3472714.3473656

Permission to make digital or hard copies of all or part of this work for personal or classroom use is granted without fee provided that copies are not made or distributed for profit or commercial advantage and that copies bear this notice and the full citation on the first page. Copyrights for components of this work owned by others than the author(s) must be honored. Abstracting with credit is permitted. To copy otherwise, or republish, to post on servers or to redistribute to lists, requires prior specific permission and/or a fee. Request permissions from permissions@acm.org.

SIGDOC '21, October 12-14, 2021, Virtual Event, USA

(C) 2021 Copyright held by the owner/author(s). Publication rights licensed to ACM

ACM ISBN 978-1-4503-8628-9/21/10 . \$ $\$ 15.00$

https://doi.org/10.1145/3472714.3473656

\section{INTRODUCTION: QUESTIONS OF USE \& USABILITY}

In the introductory professional and technical communication (PTC) course that I have taught to university students over the years, called "WR-227" in Oregon, classes are reliability about 50 percent computer science majors, 25 percent engineering majors (electrical, environmental, etc.), and the rest a range of disciplines across the colleges of various sciences and arts at the university, from biology to business majors and beyond. Students range in age, expertise, experience, and linguistic level, from teens to older professionals and veterans to international students.

In recent years in my PTC courses, I have used open educational resources (OERs), which, broadly speaking, are digital textbook websites that can be purchased as low-cost print copies but are mostly read freely online with web browsers or downloaded as an ebook file of some type. This can include HTML, EPUB, digital and enhanced PDF, MOBI, HTMLBook, XHTML, OpenDocument, Google Docs, and more. Some OERs for PTC also include video embeds and channels (YouTube, TED Talks, Vimeo) and other low-cost education materials. There are a few reasons for using OERs for introductory PTC. After surveying the field of OERs for PTC, much of the basic information of introductory technical communication seems to have been published and reproduced in various iterations in the creative commons, and this has been one place to save students money given that some commercial PTC textbooks range anywhere from $\$ 50-\$ 115$, not always including access to the digital version. Open access to free and low-cost educational resources also increases efficacy and intellectual equity for anyone who is in a low-income situation, busy working, currently unemployed, parenting kids, at-risk, underserved, without literary sponsorship, or otherwise lacking access to a PTC textbook or any textbook in their discipline [1]. This is part of a growing trend. Even before the pandemic, increasing amounts of institutions and instructors were turning to free, low-cost, easy-to-find, dependable teaching materials. The OER publisher OpenStax at Rice University, which has been around since the early days of the OER movement, has estimated that student savings as of a result of its OERs have passed the billion-dollar mark in recent years [2]. Then the pandemic forced droves of instructors and their students online, and many more instructors suddenly found themselves searching for authoritative online academic materials and students found themselves using more digital textbooks in various formats, from online web texts to PDFs to other modes of viewing. 


\subsection{Problem Statement}

Performing an internet search of OERs for PTC online returns no clear, definitive set of options to choose from. Instead, search results can resemble more of a bountiful cornucopia of choices, from self-published titles (e.g., single PDF texts) to third-party content management platforms where students can download multiple file formats, register their own accounts, and annotate and share thoughts on the text. The problem is that if institutions and their PTC programs cannot or do not offer their instructors reliable, authoritative online OERs for PTC, then instructors (e.g., a new graduate teaching student or a seasoned professional looking for new OER options) can be left asking their colleagues for leads or navigating an abundance of choices on their own, with several search engines and databases to choose from and options to wade through what they do and do not cover (e.g., MERLOT.org, OERCommons.org, OASIS.Geneseo.edu, OER.deepwebaccess.com). For example, the keyword "technical communication" on MERLOT currently returns 296 results. While most of the results are easy to eliminate, just combing through top search results from one or more platforms and databases alone can be time-intensive and overwhelming - not only for new PTC instructors, many of whom do not have STEM backgrounds (e.g., literary studies majors, communications majors, graduate teaching assistants and doctoral candidates from the English department), but also for seasoned PTC instructors, who are instead new to OERs and trying to integrate them into their own syllabus. It is hard to know what option is best and if another better option is somehow being missed. Add to this that even amid finding, adopting, and adapting OERs for PTC, there are questions of usability, and whether they are even being used by students and in what formats.

\subsection{Current Solutions}

On the international to national level, UNESCO published formal declarations on OERs in 2002 [3] and 2012 [4], but in nearly two decades since the first, the disciplinary/industry level no national/federal platform or infrastructure formally exists for OERs for PTC. Most recently on the federal level in the United States, legislation for OERs has existed in the form of the Affordable Textbook Act, which represents a potential pathway for OERs to be adopted more broadly in America, but the act has been introduced four times without being passed by U.S. Congress [5]. The Department of Education's National Education Technology Plan, headed by the Office of Educational Technology, launched a “\#GoOpen” initiative in 2017 to support states, districts, and educators with using OER materials to transform the use of openly licensed educational resources for teaching and learning. The National Endowment for the Humanities, an independent federal agency, also supports open-source web book publishers. For the most part, however, OER development has largely been handles by the states, their academic institutions, and various nonprofit and philanthropic organizations and activities around the country (William and Flora Hewlett Foundation, Andrew W. Mellon Foundation, and others).

On the statewide level, both Oregon and Washington state have been early OER adopters and have launched their own initiatives to develop and encourage the use of free and low-cost teaching materials in applicable courses, and they offer their own OERs for
PTC, such as OpenOregon's Technical Writing and the Washington State Board's Technical Writing for ENG 235 [6]. Other states include Affordable Learning Georgia (OpenALG) and Kennesaw State University's Online Technical Communication [7], which is a remix of David McMurrey's original Online Technical Writing, developed while McMurrey was teaching at Austen Community College [8]. There are others throughout the United States and many in Canada, including OERs for PTC from BCcampus. However, some states do not offer OER options, in which case, this is left to higher ed, i.e., university and colleges, who have been the de-facto producers of most OERs.

\subsection{Opportunities}

At academic institutions, libraries will sometimes take on the role of publishing and archiving materials. Here at Portland State University, for example, the Millar Library offered the PTC program a grant to create resources for their OER initiative. My journey as a faculty user of OERs turned into a researcher's journey when I became a member of the group of PTC instructors tasked to create instructor resources for the adoption of OERs in introductory technical writing courses (WR-227) at the university. To meet this goal, rather than spend energy authoring our own online textbook from scratch, the team opted to build an instructor's resource guide of OERs for PTC, a compendium and analysis designed to education instructions while also vetting and recommending resources that currently exist and are commonly used, authoritative, and historically dependable [9].

The primary aim of the resource guide was, and continues to be, to reduce the primarily adjunct and graduate assistant instructor labor required for finding relevant, quality OERs and other no-costto-student resources for introductory technical writing courses. Compositionally, the guide begins with suggestions for how to choose OER resources for a technical writing course and then reviews commonly used titles. In addition to a tabulated analysis of several recommended OERs for PTC, there is a topic-based resource for instructors searching for dozens of specialized technical writing topics. Instructors can view the guide with different devices in multiple formats: enhanced PDF, Google Docs, Microsoft Word, or EPUB, and there is an open-access video on OpenOregon that readers can watch which explains the who, what, when, where, why, and how of the resource guide.

When we set out to build the resource guide, we wanted to be conscious of the user's journey, and during the construction (fall, winter, and spring terms of 2019 to 2020), we workshopped drafts of the guide with WR-227 faculty, many of whom also teach at some of the local community colleges. These workshops allowed instructors to share collective experience and wisdom not only of OERs but also about incorporating them into PTC courses. After publishing the first edition in May of 2020, we continue to revise and publish new editions, including adding more sample syllabuses using OERs for PTC. Most recently, we have branched further out and added a syllabus for WR-327, Technical Report Writing.

Publishing the instructor's resource guide, however, was just the beginning. There was yet more to learn about OERs for PTC. The phases of discovery, vetting, and recommending a series of OERs for PTC just ended up creating more questions than answers, and the lengths and complexity of our working group's conversations 
about them only deepened. What had begun as discussions about the form and content of the instructor's guide evolved into more nuanced discussions about not just the value and affordances of OERs, but also their challenges and limitations, as well as what was being done to foster any needed growth or change in certain areas.

\subsection{Research Focus}

To gather more information about the range of student experiences with OER materials, our research group started conducting iterative literature reviews and regular meetings to discuss what researchers knew and didn't know about OERs broadly and OERs for PTC specifically. This set into motion a series of focus groups made up of students (IRB oversight) and instructors to better understand the electronic textbook user experience (eBUX) of OERs for PTC digital textbooks that we were recommending to them (see "User Research" below). Do PTC instructors and students use the OERs? If so, how and why? What is their sense of usability?

\subsection{Report Overview \& Purpose}

This report presents some of the topline takeaways of the most recent research on current OERs for PTC, i.e., digital textbooks, discussing results from two years of user research with students and faculty. This includes a discussion of various user types and needs, high-level OER goals and objectives, functional specifications and content requirements, interaction design and information architecture, and user feedback that fell into areas of information design, interface design, navigation design, and aesthetic. The aim is to document what users had to say about their experiences using free web-based textbooks for PTC, students primarily, but also faculty and program administrators at institutions adopting and adapting these OERs. The hope is that knowing more about both faculty and student experiences, perceptions, behaviors, etc., will help not only create content and functionality that is sensitive to users' needs, goals, and technical writing in their varied disciplines, but also advance a more strategic conversation generally about the value of digital OERs for PTC. This is also an opportunity to reflect on a quarter century of online OERs in PTC, consider the technological advancements made thus far, and ask what the future holds, as digital textbooks turn more and more into multimodal digital content management systems with information architecture and usability design in which a print copy is an output option, not the main attraction.

\section{USER RESEARCH: GATHERING STUDENT, FACULTY \& ADMIN EXPERIENCES}

Over the course of two years, three phases of user research were completed (IRB-oversight/exemption approval). The first phase of data from surveys was gathered during the spring to summer of 2020 , and the second phase during the fall of 2020, and the third in the spring of 2021.

\subsection{IRB Research Phase 1: Student \& Faculty Usability Surveys}

Our first user research phase with PTC students began the spring of 2020 and lasted into the summer. The first groups of students included three sections of Introductory Technical Writing courses
(WR-227), two in spring and one in summer $(n=24)$. These sections relied exclusively on no direct cost to students and traditional OER materials, including Kennesaw State University's digital textbook Open Technical Communication (Open-TC) [7] and David McMurrey's long-running PTC website, Online Technical Writing (OTW) [8], as well as a published textbook about engineering writing available as an ebook via the library titled IEEE Guide to Writing in the Engineering and Technical Fields by David Kmiec and Bernadette Longo. We asked students to share their experiences and attitudes of this open PTC course material in a combination of Likert-scale questions and write-in questions about their awareness, perceptions, behaviors, and experiences. To get a sense of the range of faculty attitudes and experiences with OERs, we also asked faculty involved in the professional development sessions paid for by the grant to share their thoughts and feelings in a Google Form $(n=7$, programmatic research). Faculty were asked to respond to openended write-in questions that gave us insight into their current thinking about OERs, even though not all had implemented OERs in their sections of WR-227.

During this secondary and primary research, it was readily apparent that OERs meant something different to instructors than they did to students; one group was concerned with content and the other primarily with functionality. As one might expect, this division fell along student/instructor lines. Instructors in their UX feedback of OERs for PTC spoke from pedagogical points of view, e.g., the authority of the authors, the depth of the content, its pedagogical underpinnings. For students, however, their feedback was more heavily inclined toward the usability of any given OER or, put another way, its ease of use. What the group realized was that while students may talk about the cost of OERs as the main advantage, when it comes to their use, usability matters. In other words, OERs that do not have a good UX for students might not be used, leading to low reading retention and low efficacy rates [10].

So how do students use the OERs? It was hard to find empirical evidence in the literature of any actual usage of OERs for PTC that our instructor's resource guide had been recommending. One applicable exception is a journal article from the 2018 IEEE International Professional Communication Conference, "If you build it, will they come?: Research into Students' Use of an Open Education Resources in Technical Communication" by Jonathan Arnett [11]. The article presents the high-level Google Analytics backend data of the Open-TC digital textbook, an OER for PTC that our instructor's guide recommends, which Arnett and others at Kennesaw State University have built and refined from David McMurrey's OTW textbook website. Because the article shares backend Google Analytics data to provide more empirical evidence about students' actual usage of OERs, it was not only an exciting find for our research group, but a rare glimpse of student use and behavior with an online digital textbook that several instructors at in our PTC program and colleagues we knew across the country had used as well [9].

The results in "If you built it, will they come?" however, were more sobering than the initial discovery of the article. In the end, it appeared as though many students did not necessarily answer the rhetorical call of the paper's title; backend data revealed that many students did not use Open-TC or engage with it deeply over 
the two academic terms analyzed. A small number accessed it regularly, others dipped in occasionally over the semester, and the students who used the Open-TC only skimmed it. "Further research is needed," Arnett concludes, "to determine if this result is found to persist across time and in different disciplines, and if changes to the OER design and online platform have an effect on students' access patterns" [11].

The findings in the "If you built it" article raised questions about how and if students were reading, understanding, and liking or disliking this online textbook that we were recommending in our instructor's guide, and this set the stage for the next phase of usability research. In one way, it was an experiment to design an assignment that engaged the online text more. In another way, it was a type of call to action to see if more UX research could help paint a better picture of use and usability and thereby maybe help indicate what was working and what was not working. In another way, this also presented the opportunity to analyze a popular webbased OER for PTC platforms in higher ed (Pressbooks, Manifold) that take an ebook approach to their digital textbook design, as seen through student, faculty, and writing program administrator UX points of view.

\subsection{IRB Research Phase 2: Student UX Surveys}

The second phase of student usability surveys were completed in the fall 2020. This included feedback from the one section of PTC courses at PSU in the fall $2020(n=23)$. The fall UX group completed a short weeklong exercise and documented UX feedback. In this study, a live overview of the assignment (via Zoom with videorecording and a Google Slides presentation) and assignment sheet (Google Doc) were provided to students beforehand. In two synchronous class sessions over the week that were also videoed (for future reference, including for those who could not attend the live session; a transcription option was available to students). While the assignment was discussed in the live session, questions were answered. The hope with this design was to pair the Manifold web-text with ancillary materials, an underlying collaborative set of Google Doc, Slides, and Forms to collect qualitative and quantitative data and information via a three-step user journey that simultaneously encapsulated a full learning unit with overview, reading, and exercise designed to increase OER for PTC engagement by using it as a tool to complete a writing assignment with analysis and metacognition.

The basic assignment was modeled on a user journey of three separate phases/tasks:

- Task 1: First contact (warmup). Students navigated to the Open-TC homepage and kept track via a Google Form survey of their time, perception, and behaviors as they related to first impressions.

- Task 2: Exercise completion (main event). Students in the fall UX group were asked to navigate to and read chapter 2.6 of the Open-TC, "Instructions," and then complete "Exercise 1" at the bottom of the chapter page. Students then complete the analysis exercise using chapter subsections of the chapter. Students used the Google Form to log their UX when they visited the Open-TC "Instructions" chapter page. They also kept track of how much time they spent on the exercise, rated the chapter, and described what their reading experience was like. To complete the exercise, they used the same collective assignment sheet Google Doc to post their analysis exercise so that basic interactivity data and version history could be gathered to help confirm or deny some of the qualitative data. They had to use each section of the chapter to complete the exercise.

- Task 3: UX metacognition (cooldown). Students reflected on the user experience of the Open-TC and provided written feedback to document their own UX, keeping track of time spent on pages, rating their experience, and documenting thoughts, ideas, opinions, and other feedback.

- Limitations: These tasks were completed during the pandemic. In future research, audio and video of students, faculty, and admin navigating tasks and screens could provide even more dimensions to the data and information gathered.

\subsection{IRB Research Phase 3: Student \& Instructor UX Surveys}

To follow-up on the fall 2020 survey, another survey was conducted in the spring of 2021, which expanded upon information gathered during fall 2020. This latter group of UX respondents $(n=24)$ used Open-TC [7] as the main textbook throughout the 11-week academic term, and feedback from this group helped provide information about longer-term use and usability, as well as an instructor and administrator to interview and for their UX feedback. Surveys this time were anonymous to help give respondents the room to be forthright and transparent. The course could also be observed remotely via student-user analytics options provided by the Desire2Learn learning management system. This spring section of research also included interviews with secondary users (PTC instructors) and tertiary users (PTC program administrators).

\subsection{Case Study OER for PTC}

Users navigate a sea of optional digital OERs for PTC. They come in all shapes, sizes, and formats: HTML, EPUB, digital and enhanced PDF, MOBI, HTMLBook, XHTML, OpenDocument, online DOCX, Google Docs, etc. Some web-based OERs for PTC are their own content management systems (Pressbooks, Manifold). At PSU, we created an instructor's resource guide that provides a snapshot of what is available today [9]. Students and instructors in the fall of 2020 and the spring 2021 used Open-TC [7], created by staff and contributors from the PTC program at Kennesaw State University, published by Affordable Learning Georgia (OpenALG, previously GALILEO until 2018), using Manifold (whose design is also similar to Pressbooks/WordPress Multisite) for services and online hosting and Amazon as a print-on-demand supplier (\$9.40 USD per copy). Open-TC was picked because it is one of the titles recommended in our instructor's resource guide [9] for several reasons (the creativecommons content ancestry spans decades, the current Open-TC has its own editorial backstory, and its platform speaks to a popular form of open-source publishing in higher-education), but recent analytics data from the publisher revealed questions about its actual use, which was somewhat surprising given its content and overall high marks on usability.

2.4.1 Creative Commons Content History. Open-TC is a "remix" of McMurrey's Online Technical Writing $(O T W)$ [8], one of the first 
and what appears to be the longest running open online textbook devoted to PTC. Before the term "OER" was coined in 2002 by UNESCO, open access had been rising in popularity decades before. With the blossoming of the internet and its rapidly expanding creative commons in the early ' 90 s, for example, Purdue University was launching its Online Writing Lab, Wayne Hodgins was spearheading early online open-ed concepts like the "learning object" architecture, and James Spohrer was being awarded a National Science Foundation (NSF) grant for "educational object economies," which would eventually result in MERLOT.org in 1997. OpenStax CNX was developed by Richard Baraniuk at Rice University in 1999 as Connexions. PTC also has its origins in this time period as well.

PTC had its own contributors too. In fact, the same year that MERLOT.org went live, 1997, David McMurrey, who was teaching at Austin Community College (ACC), published his OTW website with the primary goal of saving his students money [12]. McMurrey had been helping to modernize the ACC campus and, before ACC and the $O T W$, had been at IBM and had trained the company's technical writers. A quarter century later, McMurrey's website still exists online today, and many instructors still use it. Although, the content is no longer updated and the only way to view the site is online, much of it is in some ways timeless and McMurrey's decades of vetting this content with students gives the OTW time-tested credentials.

2.4.2 Editorial Iterations. McMurrey's creative commons contributions to the early world of OERs for PTC have been given new life in many different OER iterations, including here in Oregon with OpenOregon's Technical Writing. This also includes Open-TC. What makes this particular adaptation of OTW is the level of iterative editorial work and interactivity that has been put into Open-TC. At this point in its fourth edition, Open-TC online textbook has been developed under more than a dozen grant rounds from OpenALG. This also includes two major redesigns and experimenting with multiple modalities. The first iteration of Open-TC was a basic ' $90 \mathrm{~s}$ style website in terms of graphics and colors. Single-page chapters required a lot of scrolling. This was when the digital textbook was known as "Sexy Technical Communication," a nomenclature with a story unto its own described in its "Letter from the Project Manager," which serves as the preface of the online textbook. After struggling to get traction with users in early versions, much of the design compared to today's edition has changed. Contributors and editors of Open-TC have modernized the content and added a lot to the original content. This includes chapter-opening summaries, new sections, chapter-ending exercises, and sample ancillary materials for instructors, all on a platform that provides a more streamline UX and provide content for faculty while giving students most of the UX functionality that they need. What Open-TC has essentially done with $O T W$ is to revise and edit content and feed it through a different information architecture with more developer tools, authoring capabilities, and user options for engagement with the text and others reading the text.

While the remixed content has largely been successful, students have pointed out when older elements have for them contrasted with newer ones. For example, older graphics in content will not fit with the newer color scheme (yellow color scheme verses red-based theme). One student, for example, a programmer, noted that in chapters, it "felt like some of the colors used didn't really go together but that is a small manner and is probably more of a preference thing." Of course, one of the most common types of editorial artifacts are images, which after the text is edited often become an afterthought, or don't have time in the editorial phases, or there isn't enough budget, or pressing need, to make new figures. Indeed, this seems to be the case with much of Open-TC, much of the original webpage typography is still used and could perhaps out of all the content use a revisited update. There are other artifacts, as well, like older dates on student examples (e.g., March 09, 2019), certain technologies have changed (technical description of a DVD), or a new pedagogical learning objective is missing a corresponding section (no "Ethics" or "Diversity, Equity, and Inclusion" section). Sometimes, students in the feedback also noticed the different writing voices between all the authors of this remixed creative commons content (McMurrey's voice versus the Open-TC team's collective authorship, who have remixed and edited different chapters of the original McMurrey content). Other than these small excursions from the reading experience, overall, Open-TC scored well with student users on ease of use and effectiveness, and it covers many of the number of PTC topics that it covered in our resource guide [9].

2.4.3 Publishing Technologies. OpenALG's Open-TC owes its relatively smooth UX to its third-party managed hosting services provider, Manifold (https://manifoldapp.org/), an open-source, open-access publishing platform that caters to universities and book publishers. Launched as the result of a 2012 online publication of Debates in the Digital Humanities, Manifold is a collaboration between the CUNY Graduate Center, the University of Minnesota Press, and Cast Iron Coding with grant support from the Andrew W. Mellon Foundation and National Endowment for the Humanities. Manifold software features include the ability for annotation of webtexts, community experience technologies, and other added services. Currently, the Manifold version of Open-TC only offers downloads of the digital textbook in whole PDF, Word, and HTML/ZIP (no ebook formats like EPUB or MOBI). There is a print-on-demand option through Amazon (\$9.40 USD).

At many points in this report, Manifold is contrasted with Pressbooks (https://pressbooks.org/). OERs for PTC such as OpenOregon's Technical Writing use the Pressbooks platform, which is another open-source content management system designed for creating ebooks that is of the same era. Released in 2011 under the GPL v3.0 license, Pressbooks is built on top of a WordPress Multisite turned into a book content management system (with changes to the administrative interface, web presentation layer, and export routines). While Manifold and Pressbooks share a lot of similarities (e.g., homepage with a splash panel, book cover, and table of contents, the information architecture of part/chapter, and others), Pressbooks offers multiple formats that digital textbooks can be exported to (HTML, EPUB, digital and print PDF, MOBI, HTMLBook, XHTML, OpenDocument), and a low-cost version of OpenOregon's Technical Writing can be ordered from Lulu.com (\$14.66 USD). Based in Montreal, Canada, and developed by Book Oven, Inc., Pressbooks seems to have catered largely to small publishers and individual self-publishing authors in its beginning, but also then pivoted to 
wider used among educational institutions and academic presses in recent years (University of California, Berkeley, BCcampus, Virginia Tech, University of Guelph, Idaho State Board of Education). There is also PressbooksEdu, which supports institutional hosting. At PSU, an institutional subscription to Pressbooks was purchased in 2019 through the Office of Academic Innovation ( \$5,000/year).

Manifold does automatically offer as many formats of the digital textbook as Pressbooks (at least OpenALG's Open-TC compared to OpenOregon's Technical Writing), both are similarly concentrated on a web-based e-textbook user experience: Manifold's UX approach, for example, is perhaps summed up in the marketing language on their homepage: "Shouldn't the web be a nicer place to read books"? This is also akin to the UX approach that Pressbooks itself takes, which helps academic institutions and publishers, as well as self-publishers, handle the more technical aspects of creating and formatting digital textbooks for different platforms and user experiences. Much like Pressbook's predecessor platform for publishing audiobooks, LibriVox, the design focus is to build tools to make it easy for people to publish and use. In one interview, founder Hugh McGuire equated his UX approach with Pressbooks to something akin that of Amazon's but for ebooks, "I think the book industry, and not just Amazon, needs to spend a lot more time and energy trying to deliver reader happiness," i.e., focused on well-formed, seamless, professional UX [13].

The type of UX focus on reading web books discussed above seems to play out in feedback from students on Open OpenALG's Open-TC. Overall, Open-TC scored high on usability, usually a 4 or 5 on a Likert-scale approval rating of students surveyed. No student gave a 0 or 1 rating when asked. This makes sense given the attention to UX. Still, users noted some limits to the usability, issues of readability, and questions about legacy content and inherited information design, which relates not just to Manifold, but similar web-based e-textbook platforms like Pressbooks.

\section{DISCUSSION: THE ELEMENTS OF UX FOR OERS ABOUT PTC}

The sections below discuss the observations and behaviors of students enrolled in introductory PTC courses using digital OERs, which includes input from faculty and writing program administrators. Because of the small scale of the student and faculty research, as well as the limited scope of the OERs considered in this user research, the aim is not to report the frequency of student and faculty responses, or to generalize their attitudes and experiences with OERs, nor is it to insist on any research methodology or judge any OERs. However, the rationale is that if an experience, challenge, concern, issue, etc., is raised by one person in a user group, then this could potentially represent others in the group and beyond. The sections in this discussion move from more abstract topics (e.g., student needs and faculty objectives) to more concrete ones (e.g., user interfaces and navigation).

\subsection{User Group Profiles}

Designing a device-agnostic digital OER for PTC on the web with a print-copy version requires including content and designing functionality for different user groups, students of numerous disciplines primarily, but also instructors of varying degrees of experience secondarily, and there are also tertiary audiences to consider, such as administrators and other institutional representatives, as well as oversight councils and other organizations that concentrate on policies and regulatory guidelines and practices. Finally, there is the public reader. Below explores the primary, secondary, tertiary, and other user/reader groups of OERs for PTC.

3.1.1 Primary Users - PTC Students. There is always a diverse array of students in introductory technical writing courses. An instructor could encounter an engineer in her fifties working for a city government bureau and returning to school to hone her writing skills. Another student could be a physicist in his thirties with a military background who has worked on aircraft carriers. Yet another could be an engineer in their twenties helping launch satellites into space. There might be a freshman computer scientist fresh out of high school with an internship at a local tech company. Each has their own story, and each has a unique set of needs and shared needs with others. From the multidisciplinary nature of PTC courses, getting OERs right can be a difficult ask when it comes to speaking to all the different segments of users/readers within the primary readership, including but not limited to the following.

Majors and Minors: OERs for PTC are used in multidisciplinary contexts. PTC courses cater to a wide range of writing in the disciplines: science, technology, engineering, arts, and mathematics, as well as medicine and public health and business administration, economic, and finance. The makeup of the fall 2020 UX focus group represented a common composition of majors and minors in this type of course, with 50 percent made up of computer science (CS) majors $(n=12)$, but also included an electrical engineer (1), environmental engineers (2) and civil engineer (1), as well as business administrators (4), biological scientists (2), and technical communicators (2). Sometimes, there will be even more CS majors in the group, as the spring 2021 UX group showed, which was composed of CS and electrical engineers (17), but also biologists (2) and environmental scientist, public health specialist, speech and hearing scientist, chemist, technical communicator, environmental engineer, and psychologist. While these disciplines represent the common types, many other majors take PTC courses (e.g., economists, accountants, mathematicians, musicians, chemists, photographers, naturopathic practitioners, theatre artists, graphic designers, nondeclared majors, and more).

Grade Levels: OERs for PTC are used in multi-grade-level contexts. The grade-level composition in a class will vary, which shows that OERs for PTC must appeal to many academic maturity levels. The fall 2021 focus group, for example, ranged from freshmen (1) and sophomore (3) to junior (8) and senior (12). As often is the case with required introductory writing classes, students will sometimes leave PTC classes until their last two years. This results in more mature groups sometimes, which often means, like it did in the group above, that students have more experience with professional groups and settings at the university or college, as well as more industry experience in the field, which brings with it certain needs and expectations regarding OERs for PTC. The composition will of course fluctuate. In the spring of 2021, for example, the center of gravity shifted to sophomores and juniors: freshmen (1), sophomore 
(9), junior (8), senior (4), and post-baccalaureate (2). Regardless, the fact remains that multiple grade levels will apply.

Ages and Experience: OERs for PTC are used by multiple ages. As with most PTC courses, every section is a mix of younger and older students. The age maturity level in PTC classes will range from age 18 and right out of high school, to 50- and 60-year-olds furthering their education. With age brings more experience levels, from professionals in industry to parents with kids to returning veterans. In the fall 2020 group, for example, the age ranged from 19 to 31 with most 20-21 (6) and the rest in their mid- and late20 s, save a 31-year-old. With age, maturity, and experience come expressed wants and needs (e.g., examples of workplace writing artifacts, like a recommendation report from a large corporate IT company, an internal guideline document at an engineering firm, and so on, see also the discussion in the "Content Requirements" section below).

Technologies: OERs for PTC are used in multimodal contexts, mostly digital but also print. It always helps beforehand to survey students on the types of devices they will be using for the course and if they will use/need print copies because a handful students order the print version of the book, some will print pages at home, but print-dependent students still exist and should be considered when creating a digital OER. However, most will use the online digital version or an exported file (e.g., PDF, especially if it is provided by the instructor, as we found in the spring 2020 UX focus group). When it came to devices/hardware, many students use laptops, but also desktop computers, and also phones and tablets. Top results of manufacturers in surveys included MacBook, iMac, iPad, and iPhone models to Windows-based Lenovo, Acer, ASUS, Dell, HP, Razer, Microsoft, Sony, and MSI. In these PTC groups are also those computer scientists and electrical and mechanical engineers who invariably use and build their own computers. Early in the pandemic, the number of rental devices saw an uptick as well. Related to browsers, most students use Google Chrome (likely because of the Google technology being used at PSU); however, there were a handful of Firefox users. In the student groups surveyed in the fall of 2020 and spring of 2021, some used tablets and phones, but none reported using an e-reader of some type (e.g., Nook, Kindle, although Open-TC does not offer a MOBI or EPUB version currently). Perhaps the biggest concern with technology has been internet access, wireless or otherwise, which could be intermittent on campus. Wireless access was an issue during high use times in the pandemic. During research students also lost access during both wildfire and snowstorm outages. Other students were in areas of the state that did not have reliable internet and infrastructure. One instructor had heard on public radio that students in the area sometimes use company parking lots for free customer Wi-Fi access. These are some of the inherent issues of free web textbooks. The downside of the OERs that are purely online means that they are accessible anywhere, except where there is no Wi-Fi. Students must have internet access, which points to a common gap with most online OERs without a print-copy option; they do not help the student who does not have internet access. However, there are examples of OERs for PTC that do have print-on-demand copies, like Open-TC (discussed further in "Content Requirements").
Locations: OERs for PTC online are used in multinational settings. Because user research was completed remotely during the pandemic, when the spring, summer, and fall 2020 groups were surveyed about their location, some were quarantining on campus, but others were in several areas of the United States and some international students had travelled back to their home countries. Given the diverse locations and easy online access, using open-source OERs for PTC is a way for all students to access an authoritative PTC textbook in multiple download formats (avoid book price and, if applicable, shipping and handling), including a mailable print copy, if necessary, when bookstores across the university bookstore was closed. The upside of having OERs accessible online is that they can be translated by browser translators like Google's webpage translation features, since few OERs have a budget for customized translations for the many PTC students across the globe.

Awareness: OERs for PTC are used with varying levels of a wareness. Previous experience and awareness of OERs among students will vary toward the low-awareness end, but the number seems to be growing, and it is not uncommon for more than a few to have had experience with OERs, fewer with OERs for PTC. This was true with the fall 2020 group, as well. Other than free library resources, around two thirds of participants indicated they "never used" OERs before (15), with the rest choosing "some experience" (8). Most users were new to this particular OER for PTC (21) while others had seen it before (2). Students surveyed were also asked about past OER experience and mentioned texts from OpenStax (chemistry, physics, and calculus) and CogBooks, but also massive open online courses (MOOC) like those from Khan Academy (math and coding), Udemy, Brilliant (math), and HarvardX/edX lectures on YouTube (computer programming).

In the end, the rising awareness of students is connected to a rising awareness with the secondary user group, their instructors/faculty, who are the ones who read the OERs for PTC first, before students, and then introduce these free and low-cost academic resources to them.

3.1.2 Secondary Users - PTC Faculty. When it comes to adopters and adapters of OERs, one noticeable segmentation among faculty users includes: (i) newer instructors, such as graduate teaching assistants, adjuncts, and full-time professors, who may have a major other than a PTC degree, including communications majors, non-fiction majors, publishing majors, literary studies majors, etc., along with (ii) experienced PTC instructors who are not new to PTC but new to OERs. Both are looking to find resources and materials that are not only authoritative and appealing to students but also free and, if possible, are offered in a low-cost print version. Instructors look to their libraries for resources, ask colleagues for leads, and perform their own internet searches using special OER search engines, such as MERLOT.org or OERCommons.org.

Even though faculty are secondary readers, after the primary/target student audience, instructors are also a gatekeeping audience because they read the textbook first and then give their students the resource. The traditional textbook publishing industry knows that finding and selling to faculty to use their textbook is one of the methods for getting copies sold. The same principle applies with OERs for PTC; getting faculty to adopt the text is the key to having their students use it. That is why ancillary material provided 
by the OER (PTC exercises, syllabus examples, sample assignment sheets, sample questions about the reading, etc.) can be a powerful draw for instructors, particularly new ones, because the extra teaching material makes it easier on the instructor to adapt and adopt the OER. Many of today's OERs for PTC come with ancillary material like this, including OpenOregon's Technical Writing and the Washington State Board's Technical Writing for ENG 235 [6]. Other states include OpenALG/Kennesaw State University's Online Technical Communication [7].

3.1.3 Tertiary \& Other Users - PTC Administrators. Of course, other than faculty, there are also tertiary audiences, including representatives of internal or external oversight/stakeholder groups, such as program directors and administrators of departments at academic institutions. These individuals approach OERs for PTC from administrative points of view and are not really reading the content for instruction, but rather for other goals, metrics, and dimensions, like authority, quality, efficacy, etc. They also act as a gatekeeping audience who can affect faculty choices. Other audiences outside of this are officials at government agencies and policy makers related to higher ed, as well as individuals in the education industry, at nonprofits and other philanthropic organizations, and in regulatory organizations. Beyond this are individuals from the public not necessarily connected to PTC but who make up the group that forms popular opinion about OERs for PTC, and who may encounter one during a search on, for instance, how to write a recommendation report or technical proposal, or perhaps while voting for an OERrelated legislative measure on a local or state ballot or hearing about it in the news.

\subsection{User Needs \& Product Objectives}

Based on the user group segmentation of OERs for PTC, strategically, they must satisfy more than one type of reader. There are student user needs but also faculty adapter/adopter needs, as well tertiary readers and beyond. Goals are different for different readerships, i.e., the user goals of students diverge from those of faculty and administrators, but author/publisher objectives and users' needs are also inextricably linked.

- The goal of the instructor, who is backed by the program director and working as a representative of the institution, is to use authoritative, current OERs that match institutional goals, objectives, and learning outcomes while also educating and enriching the student.

- The goal of the student is to use the OER to learn, i.e., to attain the learning outcomes, but also to get a good grade in class, graduate with as high a GPA as possible, and hopefully use their GPA and what they learned from the OER for PTC in a workplace or otherwise professional setting.

Strategic concerns for OERs of PTC ebb and flow between user needs: students need the OERs for PTC, like any good textbook, to be a direct tool for gaining knowledge while attaining a good GPA to be applied toward higher study or job; the institution needs a method of educating and academically exercising individuals in the student body and then assessing, evaluating, and grading them. Although the student and instructor are both using the same OER, one precedes and guides the other, and they need slightly different content/functional elements to be combined into one place for their relative user journeys to go smoothly, first instructors and program administrators, then students. In their feedback, faculty, directors, administrators, et al., leaned toward information-related needs (content quality and depth), while the students leaned toward functionality-related needs (information design, interactivity, navigation). In the same way, design strategy considerations go back and forth between the OER "product" as a matter of functionality versus one of information/content, and a well-balanced OER for PTC must provide both.

3.2.1 Student User Needs: Easy to Use \& Understand. In the spring 2021 student surveys, students were asked to write a short response in their own words about what makes a textbook "effective" in their opinions and then rate Open-TC. Language in the feedback signaled the same pattern that we had seen in our previous student surveys: responses were connected to use and usability. Out of seventeen short essay responses, for example, more than a dozen, almost three-quarters of the group, cited usability features in their responses to what makes OERs effective: good interface, easy-toread information, easy-to-read font, easily navigated (mentioned 2 times), easily/quickly accessible (2), well organized (3), and search options (3). In a few words: "easy" to "understand" (content) and "use" (functionality). Open-TC scored well overall too: nearly threequarters of the group of seventeen said that the online textbook was effective (4) or highly effective (8), with none marking "not at all effective."

The above results supported previous survey results from our first phase of student and faculty surveys, where we asked students and faculty to choose their top five of thirteen listed items that were most important to them about textbooks. Across the twentyfour respondents of the focus group, the top five most frequently listed choices were: (1=top) easy to understand, (2) low/no cost, (3) engaging/interesting, (4) easy to use, and (5) easy to navigate. Regarding number 2 on this list, there is no doubt that cost is factor with students. One student related that some of his friends avoid classes with pricey textbooks. The instructor using the Open-TC in his spring 2021 introductory PTC class mentioned that students noted being grateful not to have to buy a book, and student survey responses from his students confirmed this. Other than cost, what is also noticeable in this list above, perhaps not surprisingly, is that four of these five priorities above relate directly to the UX that students have with the text. Based on the students' expressed priorities, the UX should be "easy" and "engaging" [10]. In other words, while cost matters, so does usability; use perhaps depends on usability in some respects, but that is sometimes hard to see for faculty and administrators who are more focused on the quality and quantity of content. When, for example, a chapter is long and filled with information-rich text, but a wall of text makes it hard to read, and no way of jumping from subsection to subsection is available, making it hard to navigate and return to later, then students spend part of their time and mental energy navigating, reading, and processing large swaths of text. This is time and energy that could be spent more efficiently with the information design. Thus, the process of learning can be made easier or harder by the construction of the OER for PTC.

3.2.2 Faculty \& Admin Needs: Product Objectives as Learning Outcomes. The way students prioritize their UX contrasted with faculty 
who, like the students, were asked to choose their top five of thirteen listed items that were most important to them about textbook. In fact, faculty priorities were among the least frequently chosen of the items that students chose, including the "Features in-depth coverage" and "Visually appealing" [10]. This was not necessarily a new finding for the group. Concerns of quality and substantive content had been a theme going back to our workshops for the instructor's resource guide. Instructors were finding a lot of unwanted artifacts. Some OERs for PTC have broken links, look out-of-date, are text heavy, lack fresh design elements, and/or are difficult to navigate, and faculty survey feedback expressed some amount of concern with the general quality of OERs for PTC and other digital texts, including the depth and breadth of the content in the text, the information design of the text, the consistency of the design and context across multiple course texts, and how the ethos of the instructor is impacted by the perceived quality of the text by students. OERs seem to have also developed a reputation that precedes them. In the literature, for example, a full-time mathematics professor in one OER study framed faculty sentiment as low cost equaling low quality and thus leading to low efficacy: "I would like to find material at low cost, but high quality is more important" [15].

Of course, the production quality and depth of content of any textbook is in many ways mitigated by the skill and experience of the instructor, as well as the training and support provided by the program and institution. Although it represents more effort in some ways, expert PTC instructors can make almost any textbook work, high quality or low, content lacking or not (e.g., help students navigate sub-optimal educational texts, fill in gaps in missing or confusing material, draw mental pictures that are not drawn by text and images in the textbook, describe a workplace context not covered by an OER for PTC), but this might be harder for newer instructors, who could also be concerned about developing an authoritative and credible identity as an instructor of technical writing (their pedagogy, curriculum, readings, writing assignments). The overall production quality of the texts in this case can matter to some new teachers who might want to lean on the authority of the text as a replacement for their own lack of experience with teaching PTC courses. On the other side of the experience spectrum, apart from new instructors, seasoned PTC instructors who have found a high-cost traditional commercial textbook might also be less likely to adopt and adapt to a lower-quality online version.

For secondary and tertiary groups, the project objectives of OERs for PTC come down not only to production value, but also how the content effectively catalyzes learning outcomes. Learning outcomes are set for a course locally by academic institutions, but also by regional and state organizations and agencies. For example, the Oregon Writing and English Advisory Committee (OWEAC), which is composed of writing faculty at two- and four-year institutions across the state, publishes learning outcomes for technical writing instructors and programs who teach Introductory Technical Writing (WR-227). The OWEAC learning outcomes statement describes the knowledge, skills, abilities, and behaviors/attitudes that students should be able to demonstrate after successful completion of WR-227, which is one of two second-year courses that comprises the general education writing sequence that satisfies Oregon's Associated Arts of Transfer Degree and, at the community college level, may fulfill degree, program, and certificate requirements. It is important for OER for PTC instructors and designers to keep learning outcomes like these in scope, as these high-level goals/needs statements are crafted to reflect current best practices and objectives in the field of PTC (e.g., rhetorical awareness; critical thinking, reading, and writing; processes; knowledge of conventions; and metacognition and transfer), and they are sometimes updated to reflect new academic and pedagogical changes [14]. As it relates to OERs for PTC that currently exist, some well-known titles/sites (e.g., McMurrey's OTW) do not have objectives clearly spelled out while there are others that do (e.g., Open-TC), but this will vary from title to title, state to state, academic institution to academic institution, etc.

\subsubsection{Student Needs Contrasted with Faculty \& Admin Objectives.} Overall, student expectations for what will be taught in a technical writing course tend to be strong and generally highly conventional (focused on learning common workplace genres and style and grammar conventions). Understood within the context of functionality, students indicated that an effective OER is "easy to understand and use" in its various aspects, whereas instructors understand effective OERs more in terms of the design, content, and consistency of the text, and, along with writing program directors and other academic administrators in higher ed, are concerned with efficacy and learning outcomes. Combining all groups' needs creates the scope for identifying the various content requirements and functional specifications that come with a robust online/print OER for PTC, one whose functionality and content speak to all users at the right relative time and space.

\subsection{Content Requirements}

Both students and faculty need and use content from an OER for PTC. Students use the content, like any good textbook, to be a direct tool for gaining knowledge and which is designed to teach with its content. Faculty and program directors, on the other hand, need content for lesson plans, end-of-chapter exercises, broader writing assignments, rubrics for evaluation, and other ancillary teaching material. Other tertiary groups are looking for authorial identities, grant information, etc. Below are some takeaways on content requirements from student and faculty surveys.

3.3.1 Compositionally Designed to Teach Students. When asked what makes a textbook effective, students mentioned elements about textbooks that were designed to engage and teach students. For example, one student mentioned that she likes it when her textbook "signposts key ideas." Another wanted "plenty of examples and refreshers on earlier topics in later sections," and another wrote that "summaries and short quizzes are helpful." Another student wrote that they liked it when the textbook, syllabus, and assignments are all in conversation with each other. Each person has a different reading style and preferences for content, but there are compositional patterns of arranging diverse content types that can help different types of readers, such as parsing each chapter in clear subsections and unpacking the concepts from frontmatter to backmatter using text formatting, figures that teach the concept, and all the other compositional textbook tools available. This includes chapter-opening summaries of content to start the reading process, with chapter subsections between them that include 
images with alternative text, callouts of key information, bold or italics to highlight/signpost key terms, figures to illustrate, tables to tabulate, numbered and unnumbered lists, links to example documentation/artifacts, multi-toned formatting, followed by sample exercises, assignments, and/or quiz questions, links to references and resources, and other common textbook backmatter content. Open-TC, as an example, does a relatively comprehensive job of supplying most of this type of diverse content, adding chapter summaries, exercises, and new subsections to McMurrey's creative commons content, for instance, although perhaps even more could be done to update and diversify content even more. However, some self-published OERs for PTC do not have a lot of this content, and there are gaps that must sometimes be explained or made up for in the instructor's materials. This common occurrence is not all that surprising, given the production budgets of OERs for PTC, which can pale in comparison to traditional textbook publishing operations.

3.3.2 The Options for Print, Audio \& Other Modes. Students and instructors seem to still like to have access to a print copy or at least the ability to print out material. One older student in his late thirties, for example, although a bit of an outlier, mentioned preferring separate PDFs of chapters to print out on his printer and read the text on paper. Some students have mentioned liking print editions because they're easier to read and less reliant on internet access and connectivity. For some, readability and reading retention is benefited in print formats. Readers can provide their own analog annotation and highlights. Thus, there is a smaller but still existent demand, and as some students prefer this option. This could be connected to age, but since PTC class makeups have such a wide range in ages, access to a print option is a usability requirement for OERs in PTC courses.

However, the duel digital-print need expressed by some students is often a benchmark not met by many of the digital and webbased OERs because it is the hardest to pull off, especially on what are typically low publishing budgets to create the OER, which is often grant-based, and there are production editors to help like there would be at a traditional publisher. The problem is that it has traditionally been hard for some instructors to find a print edition of an OER for PTC that does not involve printing it out with a desktop printer, and if instructors want to create smaller PDF printouts of an OER for PTC, they must often do it themselves. The reality is that many OERs don't have the option to purchase a low-cost print copy.

Some companies (e.g., Amazon.com, Lulu, com) offer a printon-demand option for OER authors and publishers. For example, Open-TC's Manifold has a light grey button on its homepage to "Buy Print Copy (\$9.40)" from Amazon. What students get is a relatively low-cost version that covers printing and shipping cost, not a $\$ 50$ - to $\$ 115$-dollar edition. Students noticed the buy-print-copy button in their survey feedback, but when asked if anyone had purchased the print edition, no one had, highlighting the tension with presenting a print edition option; it is a relative luxury that a low number of students might use it if not mandated by the instructor and/or program to buy the print copy.

On the topic of multimodal options are even more modes to consider, which bring in potential further production costs but also represent making these e-texts even more accessible. There is the basic set of digital texts to consider offering that Open-TC currently does not (HTML, EPUB, digital and print PDF, MOBI, HTMLBook, XHTML, OpenDocument), but there are other modes to consider as well. One user, for example, mentioned that an audio version would be helpful, and this includes considerations for screen readers, as one instructor wrote on behalf of students that "I would also like to see a read aloud feature for the sight impaired." Currently, and audiobook type of feature does not exist with Open-TC, or OpenOregon's Technical Writing, or on the Pressbooks platform, but the functionality does not seem too far off in the future given where text-to-audio technologies are today. For now, however, the general design idea with platforms like Pressbooks and Manifold is to create an online space that serves the textbook, but also provides access to content for this title in multiple formats, not just text and images but also audio and video.

3.3.3 The Benefits of Examples, References \& Other Resources. Many OERs for PTC do not have any up-to-date examples in concentrated repositories that provide students of different majors, and even new faculty, with applicable examples of PTC artifacts from various fields. However, based on user feedback, students are intellectually thirsty to see up-to-date PTC examples. This need was expressed not only the well-versed students with professional industry experience who wanted to see more than student-written examples, but also this was also a need expressed by young and/or inexperienced students who were interns at technical organizations. Both types of age and experience levels were interested in, and would likely be aided by seeing, actual, real-world, "ground-truth" examples of technical writing in their disciplines. This common sentiment over the years of introductory PTC instruction was expressed by one of the experienced computer scientists in a group, with years as a cyber security specialist in the military working for a third-party government contractor, who wrote, "Some back matter [examples]. . . may have been handy." One student from the spring 2021 emphasized this when they said that they wanted "plenty of examples." Another student qualified the requirement to "having good examples," and yet another student had the added idea of including annotated negative examples, e.g., "more examples of bad instructions."

While the Open-TC "backmatter" chapter "Examples, Cases, and Models Index" provides many examples of PTC writing in various professional and technical disciplines (and there are other databases of examples, such as Purdue's Online Writing Lab), students do not have, say, some instruction examples that have been hyperlinked in the "Instructions" chapter, but could, and vice versa. They have to go digging in an appendix. Furthermore, what content is available comes from McMurrey's OTW, whose content is in some cases aged and aging (e.g., examples from March 09, 2009), there are descriptions of mostly older technologies (e.g., DVDs and old iMac documentation), some links are producing 404 broken-link pages, the examples are mostly student work, not workplace examples, and the whole collection could be replaced with a much larger variety of writing for computing machinery topics and other topics across the disciplines. While some of the content is timeless and all 
of it worth keeping, and while there is appetite for more real-world documents to be added and tied to assignments and learning outcomes, in many ways, the hurdle becomes assembling a repository and keeping it updated, with the risk that it becomes quickly dated or, worse, forgotten. The number of content categories makes the compilation process more intimidating as well. So much technical communication is proprietary. It is hard to gauge if the effort to satisfy this need is worth the pros and cons.

3.3.4 A Breadth of Topics for Faculty and Program Admin. One of the more difficult things about finding an OER for PTC is getting one that covers a breadth of topics that the discipline covers. OERs for PTC have many topic areas that no current title fully covers. From the early days of building the OER instructor's guide, we had been developing a register of not just different titles but also keeping track of the section topics within these content requirements. In our OER instructor's guide, we identified approximately thirty different content categories and compared various OERs in PTC to these categories in the OER instructor's guide [9]:

- Defining Technical/Professional Writing, Correspondence (memos, letters, email), Audience Analysis, Proposals, Technical Reports, Lab Reports, Progress/Summary Reports, Standard Operational Policies \& Procedures, Recommendation and Feasibility Reports, Definition \& Description, Handbooks, Instructions, User Guides, Resumes/Cover Letters, Business Plans, Graphics/Visuals, Ethics, Document Design , Technical Editing, Writing Process/Outlines, HTML/CSS/Web Development, Collaborative/Team Writing, Usability, Intercultural Communication, Citation and Plagiarism, Information literacy, Genre Analysis, Oral Presentation, Grammar, Style, and Research.

While some OERs for PTC come close, like Open-TC and others, no single title comprehensively covered every topic identified in the guide.

3.3.5 Content for Secondary \& Tertiary Readerships. In addition to supplying content for the primary student user/reader, attracting faculty and department administrators with content can be beneficial in important ways because PTC instructors, program directors, department administrators are the gatekeepers who let the OER into the classroom. One way to consider secondary and tertiary readers is to include ancillary materials (e.g., syllabuses, exercise instructions, reading prompts, and other teaching materials), open-learning management systems for faculty and program directors, and tie-ins to APIs of proprietary LMSs (e.g., Pressbooks, MERLOT, etc., tied to Canvas, Desire2Learn, etc.). Even when whole textbooks are broken into separate chapter PDFs, this makes a difference because inserting them into a class module like Canvas or Desire2Learn is made easier for faculty creating weekly coursework and students accessing chapter content. While Open-TC does not offer single-chapter PDFs (which was requested in feedback), it is an example of this practice of speaking to / attracting faculty and admin with content. Open-TC's homepage features light grey buttons on the right side of the splash panel that take advantage of the Manifold design (similar also to Pressbooks) to have links to "extra" documentation in the splash panel that explains and elaborates on the OER. The "Access Open Course" button provides a link to the
“Access Open Course” (module on lor.instructure.com), "Request Quiz Bank" (Google Form), and "Download Ancillaries" (ZIP file for open assignments/activities, presentations, sample syllabi, and related links), and "Grant Docs" (ZIP file for proposal PDFs and report Word DOCXs). This points to a development in recent years of seeing OER textbooks attached to OER-based learning management systems (e.g., lor.instructure.com, community.canvaslms.com). Other publishers will post ancillary and class materials on a publicfacing server (e.g., drive.google.com), like the Washington State Board's Technical Writing for ENG 235 [6]. In the end, all of the above ancillary documentation examples can take time to create on behalf of the OER for PTC author/s, but when they are provided to faculty for free (especially new instructors), this presents a large amount of energy freed up to focus on adapting the ancillary material, and this can timesaver be a big draw.

\subsection{Features \& Functionality}

The technologies for creating web-based OERs for PTC has changed dramatically since their emergence on the web a quarter century ago. With newer programming languages and information architectures, the arrangement of content elements to facilitate human understanding has opened up new possibilities. Today, with the use of platforms like Manifold and Pressbooks, OERs come with more features and functions and have become much more interactive and easier to navigate. Still, individuals in user groups noted issues with the usability, including navigation and webpage interaction. Key takeaways from the student and instructor feedback are discussed below.

3.4.1 Interactive Media Design: Featured Functions vs. Actual Use. To see how far OERs for PTC have come in the last quarter century, Open-TC through Manifold offers an example of a time-tested and highly edited content fused with newer functionality. Users are provided with various ways of interacting with the text: (i) all visitors, regardless of whether they register or not, are able to search text and adjust the appearance/aesthetic of the text (choosing serif or sans-serif font, text size, night mode, and paragraph width), and (ii) by registering an account and logging in, they have access to features like annotation, highlighting, saving resources, and choosing visibility of annotations to others who are registered. From the authoring side, faculty and program directors are also able to utilize various plugins via the WordPress Multisite functionality, integrate applications like Manifold, Pressbooks, MERLOT, etc., into learning management system APIs (e.g., Canvas), as well as embed elements like sample knowledge test questions into the chapter/webpage (e.g., Google forms) and other features.

While more UX research would have to be done to survey instructors on the features they use to author OER texts, students were asked in the spring 2021 survey how much they used the reading and studying features, if any. A small number $(n=4 / 19)$ used the app features with the digital edition. Below are some high-level takeaways:

Appearance adjustment of text is used by some but not entirely apparent to all. In an attempt to make the website experience act 
more like an ebook online, common features for adjusting the text are now part of the UX for some OERs for PTC that use ebookinspired interface functionality. This includes allowing users to choose serif or sans-serif font, text size, night mode, and paragraph width.

Among all these basic features, night mode was mentioned several times with students. Night mode can come in handy functionally for users who read in the dark (e.g., reading a tablet in bed) because the negative effect causes less eye strain and provides less glare when the lights are off, but the studying is still on for those younger students in dorms who have roommates, as well as students at those who are at home sharing rooms with siblings and other relatives, and older students with domestic partners and spouses. One student mentioned that they did not see the night mode option on their own in Open-TC/Manifold until it was pointed out by the survey. This individual did not indicate the reason (remote survey did not allow for follow-up question), but there could be a chance that this student just missed the top-right part of the page because they were not concerned about registering and did not look into it further and were instead focused on the top left and middle. Perhaps this was missed because the text adjustment features are not visible on the homepage, only in chapter webpages, one-click in, a level down in the information architecture. Users, in other words, are not initiated to the text adjust features on the homepage and cannot click to adjust them here.

While some found the night mode aesthetic appealing, others pointed out the opposite preference and its associated pitfalls. Of the homepage's white text on black background of the splash panel, one of the third-year computer scientist wrote, "I'd rather read white text on a black background than the other way around." The civil engineer in the group echoed this sentiment but isolated the actual issue here, readability: "It would've been a little bit better if the background of the overview was changed/moved around. It makes certain words harder to read." One computer designer provided the solution: "my only request would be to carry over the night mode from the textbook into the main webpage." The "night mode" capability is a common feature with e-readers. Currently, the home page doesn't have the option to adjust the splash-panel background color, increase text, or use night mode, but controls on first contact might help.

Registration hesitancy could be a hurdle for featured function adoption. Registering an account on Manifold or Pressbooks was not part of any assignment or task in the surveys conducted, so the feature set that came with registering was not highly used or mentioned much in the feedback. However, this lack of registration is notable because it in a way speaks to a connection with use and students' needs. Students will not generally register and sign in if they are not made to. Annotation features must become a goal or need for all students to use them, e.g., part of a learning objective, attached to the grade, and so on; otherwise, features like these will be used by some not all. One student out of seventeen in the spring 2021 focus group registered and used some of the functions over the quarter that the class used the OER. This student who used the annotation and highlighting features "thought it was a super clean and user-friendly." This user, however, pointed out some limitations, "I wish was able to highlight and annotate the same sentence, but I was only able to do one or the other," and the majority of users, if they did take notes on the chapter content, took notes separately from the OER website, either with their own document or with another application. Even the instructor of the spring 2021 class did not in the end adopt the annotation features on Open-TC, writing that "I played around with the annotation features, but found it easier to use Adobe Acrobat, as I'm familiar with its UI [user interface]." Other mentions of third-party annotation tools included the Notability annotating software and Hypothes.is browser/website annotation extension. Otherwise, most students did not register and $\log$ in to use the personalized app features.

Some of the same aspects of registration hesitancy could be read as touted benefits to registering with a content/learning management system (it can recognize individual users, track their behavior, and connect their data and information to others in the registration database), but users do not typically register themselves on a new website if not made to as a requirement for the class, especially if it is not required to complete an assignment. Worrying about breaches of site security and privacy were cited issues, and while registration does allow for users to sign in with a Facebook account API, this did not actually work for one user when he tried, and other another user suggested weariness about linking their personal social media accounts with the school-based account. Perhaps if features like annotation were offered without the need to register, or users were showed how it worked with a motion graphic, then maybe making the annotation and highlighting features more accessible to unregistered users outside the system could lead to more registrations and adoption of the feature once users can testdrive them, but if that were even wanted or warranted, this would require more input from software developers and technical experts, and it is not clear at this point how/if it would work. However, more would have to be understood about which features really get used by students (do they log in to highlight and share with classmates and comments to faculty?), if they are meeting user needs (what if highlighting and commenting were connected to an annotation activity in the syllabus?), and if it is necessary in the end to spend developmental energy if they are not using or wanting to use features like this (what story do the analytics data tell?). In the meantime, Manifold Development plans in the fourth quarter of 2021 on developing their rich-text editor to significantly expand the current annotation and commenting interface to enable users to format content, easily add links, embed video and audio assets, and attach files to their annotations, and developments can be tracked (https://manifoldapp.org/development).

3.4.2 Homepage Design: Splash-Paneled Front Matter with TwoTiered Table of Contents. On the homepage of Open-TC, the Manifold design (also similar to the Pressbooks design on OpenOregon's Technical Writing) frontloads onto the homepage what would otherwise be pages of the traditionally Roman-numeral-paged frontmatter in a print book. This includes the creation of horizontal splashpanel space for text and book cover image that adapts responsively to a small smartphone screen or wider laptop or desktop view (more specifically, the homepage includes a splash panel, cover thumbnail, title and title page information, by-line/editor/contributor names, book description, links to the preface, related references and resources, and other ancillary content, and a table of contents, with copyright information and other publication data at the bottom of the page). 
Apart from the bright-red cover and OpenALG logo, the most popular, noticed/mentioned element on the Open-TC homepage was the two-level (part-chapter) table of contents. Overall, this design choice to have the table of contents positioned on the first page was well liked in student feedback. One student wrote a fairly common sentiment: "I personally liked after first looking at the OTC homepage how orderly it was and specifically the table of contents. It was very straight forward and you could quickly scan and see exactly what you are looking for." "Plus," another student expanded, "it lists the chapters and mini chapter points with titles as to easily click on the section needed without having to search the whole chapter for what you need." One student put it simply: it helped "navigate the text quickly."

This table of contents is a long time in the making, although a return in some ways to the original. Historically speaking, a lot of developmental work has gone into Open-TC's navigation over the years [16]. The table of contents, for example, used to be a single webpage, and navigation required going through each chapter to its end and clicking on the "next chapter" link or returning to the table-of-contents page. In the second main iteration, based on SoftChalk and CMS architecture, the visual design got an update, and the new site was easier to maintain. The table of contents was also reorganized to a numbered chapter-and-subunit system like the one currently in use; however, the table of contents used to be on the second page, which added an unavoidable click in the UX and made it easy to miss. Also, the chapter page lengths were incredibly uneven, so getting through one chapter could take sometimes eight or ten clicks to get through multiple short pages, whereas another chapter would require massive scrolling but only three clicks. Now, the table of contents is up front and center on the first page, a feature of both the Manifold (and Pressbooks) style/design. Of course, having the table of contents on the first page is nothing new; McMurrey's OTW website has always had a two-level table of contents on its homepage.

While the design choice to have a two-leveled table of contents on the homepage was liked by many, another student suggested that two levels was perhaps a bit "flat," i.e., did not reveal enough of the subsections of chapters, and could have perhaps used "some sort of drop-down menu when clicking on the chapter." This type of drop-down/accordion functionality would help those students returning to a deeper part of the chapter lower on the webpage to complete an assignment, turning a click and scroll on the homepage to a single click, no scroll. Of course, on an individual author level, Pressbooks' "Theme Options" allows OER authors to "Enable twolevel table of contents (displays headings under chapter titles)," but making more customized changes to the homepage style of the table of contents (third-level headings and below, expanding/accordion functionality) does not seem possible with the dashboard functions that currently exist, or searching any known plugins. Options in Manifold are unknown and would have to be researched further. This user feedback to break chapters into more navigable subsections, however, is a theme for users that crosses over from the homepage into the actual chapter webpages themselves.

3.4.3 Chapter Design: Webpage Lengths. In general, the feedback from students reading the online text seemed to call for chapters to be shorter and the text more chunked with more forms of content, like graphics, videos, sample knowledge-quiz questions. Related to this, and perhaps the most common refrain throughout the student surveys for McMurrey's OTW and Open-TC, was summed up by one student, who wrote "chapters were sometimes too long."

Not all users mentioned chapter length as a negative aspect of their UX. Some users were not daunted by the chapter length. For instance, one student in the fall 2020 UX group spent a half-hour reading a relatively longer assigned chapter and wrote about the chapter that "it was not a long read, very interesting information." However, for some, the length of the long chapter webpage was a lot. An engineering student in the same fall UX group reflected well on why, "a little bit too long to keep my attention through the whole section (this may be a me problem, but modern students have limited attention spans so possibly this should be considered)." This sentiment was echoed by more peers during the same chapter assignment. One student who spent a half-hour reading the chapter wrote, "I think there's tons of good information about the topic its [sic] just so much information it might be overwhelming to the user to go through all of it and fully understand it with that much information." Another student spent fifteen minutes reading the same chapter and wrote, "I find it hard to stay engaged when all I am doing is reading, so I appreciate that they have some options for interacting, but maybe finding other ways to make the reader interact." One CS major put it in terms of scrolling: "I found myself scrolling up and down a lot... It might be an organization issue from the authors part, or personal." The spring 2021 instructor who based an entire term on Open-TC also reported that students had mentioned that the reading volume was too much. Page length was also recognized by other students, faculty, and PTC program administration, who have echoed this issue of webpage-reading length in feedback gathering sessions, surveys, and interviews [10]. This issue of scrolling through text on a webpage is also brought up in Arnett's "If you build it" paper [7]. In the end, the tendency is for students to scroll through long swaths of web text without really absorbing it.

Given all of the above, OER for PTC designers, authors, etc., should perhaps be cognizant of the lengths both webpages and chapters and create elements to help users navigate lengthy webpages, e.g., headings and graphics, videos that help summarize and paraphrase concepts, links to examples or other references. Of course, no single perfect length of webpage chapter exists for every user, and topics should not strictly be subject to length, but perhaps there are bounds to consider (e.g., a word count or estimated reading time). In the fall UX group study, for example, the fewest number of people spent both the least and the most amount of time reading the assigned chapter, 5 minutes compared to 1 hour, respectively (2 in each of the extremes). 6 took 10-12 m., 7 took 15-20 m., and 5 took 30-35 m. Based on this and the general qualitative feedback about "page length," it gives some indication that 15-20 minutes might be the point at which reader retention starts to drop, as fewer make it to half an hour, since most will try to read the chapter in one sitting. There is also the amount of reading time it takes international students to read, often twice as long, as evidenced by one of the hourlong readings of this chapter by an international student in the UX group.

Because this was a common theme in feedback, there were many types of responses on the same topic. Some of the students in their 
comments even suggested ways to perhaps solve the problem of navigating on the page. Some users called for deeper layering, possibly as an expanding drop-down or accordion option to uncover chapter subsections or components. Several students commented on the want for chapter subsections to be visible in a navigation pane of some type. Other student programmers in the UX group suggested modifications to navigational ability in the form of interactive elements embedded in the chapters to make moving between content areas easier (more fluid, intuitive, and seamless). Visualizing the content chunked into subsections (e.g., like "Navigation" pane in Microsoft Word and other desktop publishers, as well as similar panes in integrated development environments and publicfacing websites) would also allow students to see and retain the macro-outline subtopics of the chapters, not to mention that smaller devices would be able to expand and contract content containers. In this way, the chapter outline of important topics is more apparent to them in ways that require that they do this mentally instead of it being visualized in a navigation pane.

- Chapter-heading material to summarize content/key points. At the beginning of the chapter, one computer scientist working in the industry suggested a common navigational element missing from the Open-TC: While Open-TC has a summary "Objectives" section, "one suggestion that I have to improve the Open-TC is maybe having a table of contents for each section they explained, so the reader would know how many sections are there for a certain chapter to explain." One assignment-minded student pointed to more on-page navigation with opening content, writing "I would have liked to see a 'jump to exercises' button in the chapter." In other words, usability, in this case the ability to navigate chapter content, could lead to higher use and more engagement.

- Chapter body. Regarding the chapter body, one experienced computer scientist and a military veteran wrote about how much that individual liked the table of contents for the book on the chapter page, but pointed out the need for sectionby-section use: "The only thing I would've liked would've been something similar in the chapters where it was laid out with specific information in the chapter that I could jump to similar to the table of contents." An experienced electrical engineer in the group expanded on the idea: "I would add in each chapter such as 2.6 a breakdown of the headings that are listed in red on the left side of the page like a table of contents. These would be links to the specific topic on each page. I think this would allow for faster navigation of the document if you are only seeking a specific section." In many ways, this type of interface, interaction, navigation structure is the type that users of XML component content management systems (e.g., DITA, MadCap, Oxygen). This type of information and interaction design is thinking like a student using the text: they need to find the section that helps them complete the assignment, get the grade, and go on to fulfil their dreams in their career.

Navigable efficacy in this way is connected to short- and longterm goals, so it becomes a matter of use and usability in the form of utility for students. A navigation pane could also be an element that teaches the logic of PTC topics in its very construction. This is not to diminish the role and importance of good content that is designed to teach, but it is also not about the content altogether, rather the usability (e.g., quicker navigation, a better understanding of where sub-chapter components are and how they connect together). The type of navigation discussed above (in-page navigation links/pane), used by some OERs like OpenStax architecture, are becoming more of the norm and part of user expectations, but other popular publishing tools, CMSs like Pressbooks' author dashboard, for instance, do not have the ability to create navigable subsections like this without help from developers and/or perhaps some plugin. Right now, based on the underlying WordPress Multisite architecture turned ebook platform, Pressbook publications use a hierarchal node structure (parent-index-homepage to child-webpage-chapter, with frontmatter on the index and backmatter as an end webpage). Perhaps there could be call for making nodes as individual content elements/components within a chapter/webpage, and thus the chapter/webpage as a group of nodes. But then again, maybe there are even more radical changes that could be made to the content and architecture of OERs for PTC, like the methods seen with Duolingo and other platforms; what if this type of app-style were the UX model instead? What is the best conceptual model driving the information delivery, a textbook? It is not clear if there necessarily a better or worse way. The topic of conceptual models for information technology design related to OERs for PTC is discussed more below in "Information Architecture \& Interaction Design."

3.4.4 Information Architecture \& Interaction Design. The conceptual models for online and print OERs for PTC span the traditional commercial textbook model to traditional ebook models to traditional CMS or LMS website models. In many cases, the OER for PTC is a hybrid multi-modal content-learning management system web-textbook, which requires understanding different reader behavior with the print and digital versions of the exact same content in vastly different ways. Traditional print textbooks are linear for the most part, even though they can be read nonlinearly (tables of contents, lists of figures/tables, page headers, indexes, pagination). Software like Manifold and Pressbooks fuses the hierarchal CMS architecture of the WordPress Multisite with the conceptual model metaphor of a traditional textbook. In this case, all the frontmatter of the textbook is repositioned on the homepage/index, and chapter content is flowed into a single webpage.

There are pros and cons to metaphorical conceptual models that base themselves on older media, like books, magazines, and so on. Sometimes, metaphors do not get in the way of functionality (e.g., a digital page looking like it is a real page turning), until they do not work properly (the page turning is glitchy or not realistic and interrupts the reading experience). Sometimes, the metaphor risks creating collision points in reader behaviors where the traditional information design of an analog model conflicts with a parallel transfer to the information design of a digital model (e.g., the front matter of the textbook is crammed into a homepage splash panel that cannot be skipped, or the entire chapter content for a textbook is placed onto a single web page without navigable section headings). In a conceptual model that wants it both ways, print and digital, there is some sacrifice and some tension in the stretching and compressing of book/document content into webpage versus book page, and there are ways to perhaps adjust and chunk content 
so that it is even easier to parse, navigate, and serve to the user of the web textbook.

For example, the choice to include a homepage splash panel of book information text with the vertical cover of a book points to an intentional design choice baked into both the Manifold and Pressbooks interfaces and signals its metaphor: the developers of the online software have made clear their intent for OERs on this platform to replicate aspects of the book, instead of conveying a look that is more traditionally considered with a CMS or LMS, which do not use book covers on their frontpages, or any other vertical rectangle grid like this. Instead, any homepage image on a CMS or LMS is provided as a more traditional horizonal banner If not tied to the conceptual metaphor of a book, is there a reason to feature a cover image of a physical book that a low number of users purchase and see as actual books? If the information on the homepage splash panel were placed elsewhere on the page (e.g., to the bottom, under the table of contents), or deeper down a level as a page in the site map, or given a drop-down menu position, or even just compacted, this relatively radical move could open the space for rethinking what could go in this space, perhaps allowing the table of contents to move up and completely eliminate scrolling for the returning user, or perhaps it is content for the user and that the user controls, etc. Making such substantive changes to the interface design of a Manifold or Pressbooks OER for PTC would in many ways dilute this signature feature in their brand of browser-based ebooks; however, this is when the decades-long minimalism of McMurrey's OTW comes into view. The OTW's website dispenses with the frontmatter pageantry and conceptual metaphor that this website is a book; it is not. Users who return to this site again and again have a table of contents to quickly navigate from, not a homepage splash panel of information they've seen and scrolled past a hundred times.

The chapter-webpage on systems like Manifold and Pressbooks is another area where the textbook format and WordPress design collide, as evidenced with the numerous comments about chapter webpage length collected over the years, discussed above in "Chapter Design: Webpage Lengths." The length of a physical book page and a page on the web have two different dimensionalities to them. In a print book, a page fits within a chapter, but on a website like Manifold or Pressbooks, a webpage can contain an entire chapter. The experience of reading a traditional textbook chapter text on a digital textbook can feel long because users will tend read through the webpage in one reading pass, not stop at a subheading as one might with a physical book. For example, only a handful of students in the fall 2020 UX group, read the chapter in more than one sitting, and many of them reported that the chapter was long. It is also easier to bookmark a real book page than it is to bookmark a heading on a webpage, unless, as was also pointed out by students in feedback, there is a way for returning students to more easily locate the chapter subsection among the other chapter topics than scrolling. Reading will likely be on a laptop, some on a tablet or even smartphone. The smaller the device, the longer the relatively reading time can seem. Changes to information architecture and interaction design on the parent homepage and child webpages like the above would of course need the input and expertise of full-stack developers and other technical professionals. However, redesigns and repositioning of traditional books elements could, strictly speaking, create situations where multiple clicks and scrolling turn into one click with no scroll, cutting out navigation time from reading time, freeing up mental energy, meeting student user goals for ease of use and understanding on any device, whether a regular laptop, smartphone, tablet, or screen reader.

\section{CONCLUSION}

In the end - after creating an instructor's resource guide on open educational resources for professional and technical communication [9] and then completing several rounds of analyzing surveys from students, faculty, and other readers/users about their user experiences with several of the recommended digital web textbooks over the years - the whole endeavor has in many ways been a study of the past quarter century and learning where local, regional, state, federal, and international stakeholder communities stand at the present with respect to web-based OERs for PTC.

Research has revealed that in the twenty-five years that webbased OERs for PTC have been evolving, they have become increasingly complex learning-content management systems in which print has always been an output option among many formats, not the primary container. Currently, there are several well-established web-based titles with time-tested creative-commons content edited into information architectures that are more fluid functionally and sensibly sensitive to student users and their reading/engagement experiences than ever. Some of these web textbooks can be read in the dark, annotated and highlighted by individuals online, and comments can be shared and collaborated on by groups of individuals. Some digital textbooks even offer a low-cost print version, come with prebaked ancillary teaching materials, and/or can be tied to open or proprietary learning management systems. There are also OERs for PTC that are supported by state governments and follow some form of learning outcomes and objectives to satisfy faculty, program director, and department administrator needs. A couple of OERs for PTC, it could be argued in some respects, stack up against some commercial textbooks in the market, while other examples reveal broken or forgotten links, lackluster content, and other issues.

Knowing more about the reading UX of students and faculty using OERs for PTC might be useful for strengthening their appeal and efficacy for user groups. It would be interesting, too, to learn more about the use and usability of current digital OERs for PTC that have analytics and/or telemetry already set up and collecting data/info, to see, for instance, how on-page elements are tracking with regard to the metrics and dimensions connected to learning outcomes, student needs and behaviors, and other objectives or requirements. User analytics and telemetry offer data and information of student, faculty, and other users' e-reading behaviors and engagement experiences with digital textbooks in ways that analog textbooks have never been able to. User research combined with backend web analytics and telemetry provides a complementary method for informing personas and use case scenarios for the multidisciplinary, multi-aged/experienced, multimodal, multilingual, and multi-cultured categories of PTC students who use OERs. UX also helps identify end-use metrics, dimensions, goals, behaviors, etc., that can be put toward helping make beneficial modifications in information design, functions and features, interactivity and 
engagement, textual cohesion, ease of navigation, and new functionalities. This includes those issues discussed by users in feedback provided in this report (addressing lengthy chapters, adding navigation tools, etc.), but also unknown areas of usability not yet well defined in the broader literature.

With possible support from federal OER legislation and guidance in the Affordable College Textbook Act looming, yet uncertain, perhaps more research into the use, usability, and experience of students and faculty of specific OERs for PTC would be useful for helping lend information to conversations about standards and practices for states when/if the act is passed, and states are faced with adapting, adopting, or creating OERs. Apart from federal legislation passing, it would still be exciting to see a national and/or fieldwide effort of any type between academic institutions, local and state governments, nonprofits, and the private sector. Perhaps an OER for PTC project could be launched, as one example, that brings together stakeholders and higher ed advisory groups with the best and brightest professional in book publishing, instructional design, information technology, and other areas to build and host a new generation of multilingual, device-agnostic, print-and-digital OERs for PTC that not only compete at the $\$ 50-\$ 115 /$ copy level but also shift the paradigm for what OERs for PTC offer. Or maybe an OER development fund could be established, as another example, headed by an independent federal government agency and funded from portions of proceeds of sales and server space from a company like Amazon/AWS or another large corporation in publishing and/or technology willing to operate and maintain the next generation of OERs for PTC, distributed freely in both print and digital copies in multiple languages. These are just ideas.

Moonshots like the above or more modest evolutions would obviously need to involve more user research, but also more economic capital, public will, cultural cache, and legislative power than currently exist, as well as a host of other factors, but perhaps there are new models beyond the current paradigm to provide even more students with open access to PTC textbooks, especially those who are still underserved educationally and marginalized intellectually around the world because of economic and/or other circumstances. In the meantime, there are several current OERs for PTC to choose from that fulfill many of the must-have functional specifications and content requirements that users need and have been getting the job done for years.

\section{ACKNOWLEDGMENTS}

Many thanks to Sarah, Jordana, Dusty, and the Millar Library team. Thanks also Gretchen, Hyphen, and family.

\section{REFERENCES}

[1] Phillip Grimaldi, Mallick D. Basu, Andrew E. Waters, Richard G. Baraniuk. 2019. Do open educational resources improve student learning? Implications of the access hypothesis. PLoS ONE 14(3):e0212508. https://doi.org/10.1371/journal. pone. 0212508

[2] Jeff Falk. 2020. OpenStax surpasses $\$ 1$ billion in textbook savings, with wide-ranging impact on teaching, learning and student success. OpenStax.org website.https://openstax.org/press/openstax-surpasses-1-billion-textbooksavings-wide-ranging-impact-teaching-learning-and-student-success

[3] UNESCO. 2002. Forum on the Impact of Open Courseware for Higher Education in Developing Countries. Paris, 1-3 July 2002: final report. https://unesdoc.unesco. org/ark:/48223/pf0000128515

[4] UNESCO. 2012. OER Declaration. World Open Educational Resources (OER) Congress. Paris, June 20-22, 2012: http://www.unesco.org/new/fileadmin/ MULTIMEDIA/HQ/CI/CI/pdf/Events/English_Paris_OER_Declaration.pdf; see also https://en.unesco.org/oer/paris-declaration

[5] GovTrack. 2021. S. 1036 (116th): Affordable College Textbook Act. GovTrack.us. Retrieved February 17, 2021, from https://www.govtrack.us/congress/bills/116/ s1036

[6] Gross, A., Hamlin, A., Merck, B., Rubio, C., Naas, J., Savage, M., and DeSilva, M. 2017. Open Oregon Educational Resources: https://openoregon.pressbooks.pub/ technicalwriting/; see also the following Canvas course containing materials to go along with Open Oregon's Technical Writing OER: https://lor.instructure. com/resources/355626b1a0194d1782df3e605d089a5f

[7] Reardon, T., Powell, T., Arnett, J., Logan, M., Race, C., McMurrey, D., et al. 2021. Online Technical Communication. Kennesaw State. https://alg.manifoldapp.org/ projects/open-tc

[8] McMurrey, D. 2017. Online Technical Writing. https://www.prismnet.com/ hcexres/textbook/

[9] Sarah Read, Jordana Bowen, and Henry Covey. 2019. OER Guide for WR-227 Instructors: Open Educational Resources for Technical Communication. https: //pdxscholar.library.pdx.edu/pdxopen/27/

[10] Sarah Read, Jordana Bowen, and Henry Covey. 2022 (currently accepted for publication). Open Educational Resources and Technical and Professional Communication: Challenges and Opportunities Amid the OER Movement. Programmatic Perspectives. Council for Programs in Technical and Scientific Communication.

[11] Jonathan E. Arnett. 2018. If You Build It, Will They Come?: Research into Students' Use of an Open Educational Resource in Technical Communication, IEEE International Professional Communication Conference (ProComm), Toronto, ON, 207-214, doi: 10.1109/ProComm.2018.00048

[12] McMurrey, D. 2020. Correspondence. For a history of OERs, see: Bliss, T. J., \& Smith, M. (2017). A brief history of open educational resources. In: R. S. Jhangiani \& R. Biswas-Diener (Eds.), Open: The philosophy and practices that are revolutionizing education and science (pp. 9-27). London, UK: Ubiquity Press. doi:10.5334/bbc.b

[13] [8] Samantha Knoerzer. 2020. The Role of Publishers in the Changing Book Market: 5 Questions with Hugh McGuire. Learn Self-Publishing Fast (blog). https://learnselfpublishingfast.com/the-role-of-publishers-in-thechanging-book-market-5-questions-with-hugh-mcguire/

[14] Oregon Writing and English Advisory Committee (OWEAC). 2018. Outcomes Statement: Contextualizing Document for Updated OWEAC Outcomes for WR 227-2018. https://oweac.files.wordpress.com/2019/02/contextualizingdocument-for-updated-oweac-outcomes-for-wr-227-3.pdf

[15] Allen, I. E., \& Seaman, J. (2016). Opening the textbook: Educational resources in U.S. higher education, 2015-2016. Babson Park, MA: Babson Survey Research Group. Retrieved February 17, 2021, from http://www.onlinelearningsurvey.com/ reports/openingthetextbook2016.pdf

[16] Jonathan E. Arnett. 2021. Correspondence. 